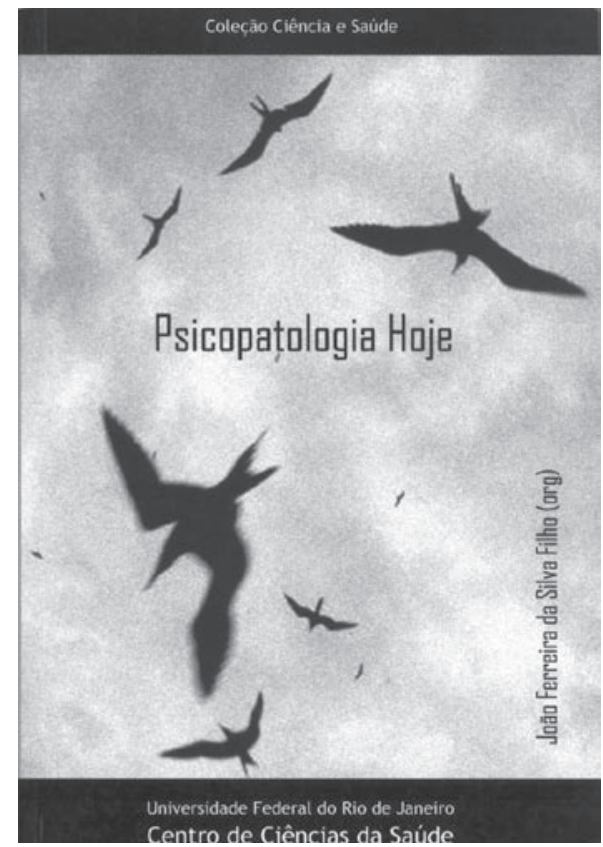

\title{
Psicopatologia hoje
}

João Ferreira da Silva Filho (org.), Editora CCS/UFRJ, 2006

Elie Cheniaux'

Hoje em dia, observamos um evidente empobrecimento da psiquiatria. Há um tecnicismo exagerado, e a clínica, ao mesmo tempo em que se tornou mais científica e mais biológica, está cada vez mais desumanizada. A objetividade tornou-se o paradigma, em detrimento dos aspectos subjetivos e intersubjetivos. A psicopatologia muitas vezes se restringe à descrição de sintomas, deixando-se de lado os aspectos compreensivos e fenomenológicos. De certa forma, os manuais diagnósticos estão substituindo os tratados de psiquiatria, e seus glossários estão sendo usados como se fossem manuais de psicopatologia. É como uma reação a tudo isso que surge a obra Psicopatologia hoje, organizada pelo professor João Ferreira da Silva Filho.

O livro é dividido em três partes e conta com dez capítulos. Na primeira parte, em "Subjetividade, valor e corporeidade: os desafios da psicopatologia", Octavio Domont de Serpa Jr. mostra as limitações de uma psicopatologia sintomatológico-criteriológica, calcada na objetividade, em comparação a uma psicopatologia fenomenológico-antropológica, relacionada à subjetividade e à intersubjetividade. Ele ainda discute os conceitos de normal e patológico e aborda o problema mente-corpo, citando especialmente os autores que defendem uma visão monista materialista, mas não reducionista. Em "Psicopatologia do senso comum: uma psicopatologia do ser social", Erotildes Maria Leal também enfatiza os aspectos intersubjetivos do adoecimento mental, argumentando que a patologia não está no indivíduo isolado, e sim em sua experiência de estar inserido no mundo e em seu contexto social. Em "Transtornos do eu: em busca do processo fundamental", Nelson Goldens-

1 Professor adjunto de Psiquiatria da Faculdade de Ciências Médicas da Universidade Estadual do Rio de Janeiro (FCM/UERJ), doutor em Psiquiatria pelo Instituto de Psiquiatria (IPUB) da UFRJ e pós-doutor pelo Instituto Alberto Luiz Coimbra de Pós-graduação e Pesquisa de Engenharia (COPPE) da UFRJ. 
tein resgata a história do conceito de esquizofrenia e defende a idéia de que os relatos pelos pacientes de suas vivências subjetivas de despersonalização são muito mais úteis para uma compreensão mais profunda dessa patologia mental do que a descrição objetiva dos sintomas psicóticos. Ainda na primeira parte, em "A psicopatologia como elemento da atenção psicossocial", Fernando Tenório e Eduardo de Carvalho Rocha discutem os aspectos estruturais da psicose e a abordagem psicossocial no tratamento da esquizofrenia.

Na segunda parte, em "A psicopatologia de Alzheimer", Annete Leibing faz uma análise histórico-cultural do mal de Alzheimer. Lilian Scheinkman, por sua vez, em "Reação exógena: a psicopatologia do delirium", apresenta a evolução do conceito de delirium e aborda os critérios diagnósticos, as classificações e os aspectos semiológicos dessa importante síndrome psiquiátrica. "Uma psicopatologia da memória", de Carlos Augusto de Mendonça Lima, é uma aula sobre as diversas alterações psicopatológicas da memória, em que são apresentados os conceitos e classificações.

Na última parte, João Ferreira, em "A psicopatologia do trabalho", aborda a questão do trabalho (ou do desemprego) como fonte de adoecimento mental. É bastante interessante sua observação de que, embora algumas doenças psiquiátricas estejam entre as que mais incapacitam para o trabalho, as classificações nosológicas não reconhecem a existência de nenhuma doença mental ocupacional. Em seguida, em "Canicule: a psicopatologia da solidão na velhice e na modernidade", Carla de Meis e Salette Maria Barros Ferreira apontam a estreita relação entre morte social, como na situação de aposentadoria na terceira idade, e morte física. Por fim, em "Trabalho científico, pós-graduação e psicopatologia: um caso na área biomédica", Rita de Cássia Ramos Louzada mostra como as exigências cada vez maiores de produtividade nos cursos de pós-graduação, particularmente quanto ao número de publicações e ao fator de impacto, podem estressar o aluno e afetar de forma significativa sua saúde mental.

A maior riqueza da obra repousa em sua proposta de diálogo, que é explicitada já na introdução, assinada por João Ferreira e Maria Tavares. Não faz sentido haver competição entre visões diferentes da psicopatologia. Os aspectos objetivos e subjetivos, científicos e clínicos, biológicos e psicológicos, objetivos e subjetivos, individuais e sociais, ou descritivos e compreensivos são complementares, e não antagônicos ou mutuamente excludentes. Uma psicopatologia sectária, que empobrece o estudo do adoecimento e da saúde mental, deve ser criticada, o que o livro faz, com grande vigor. 